
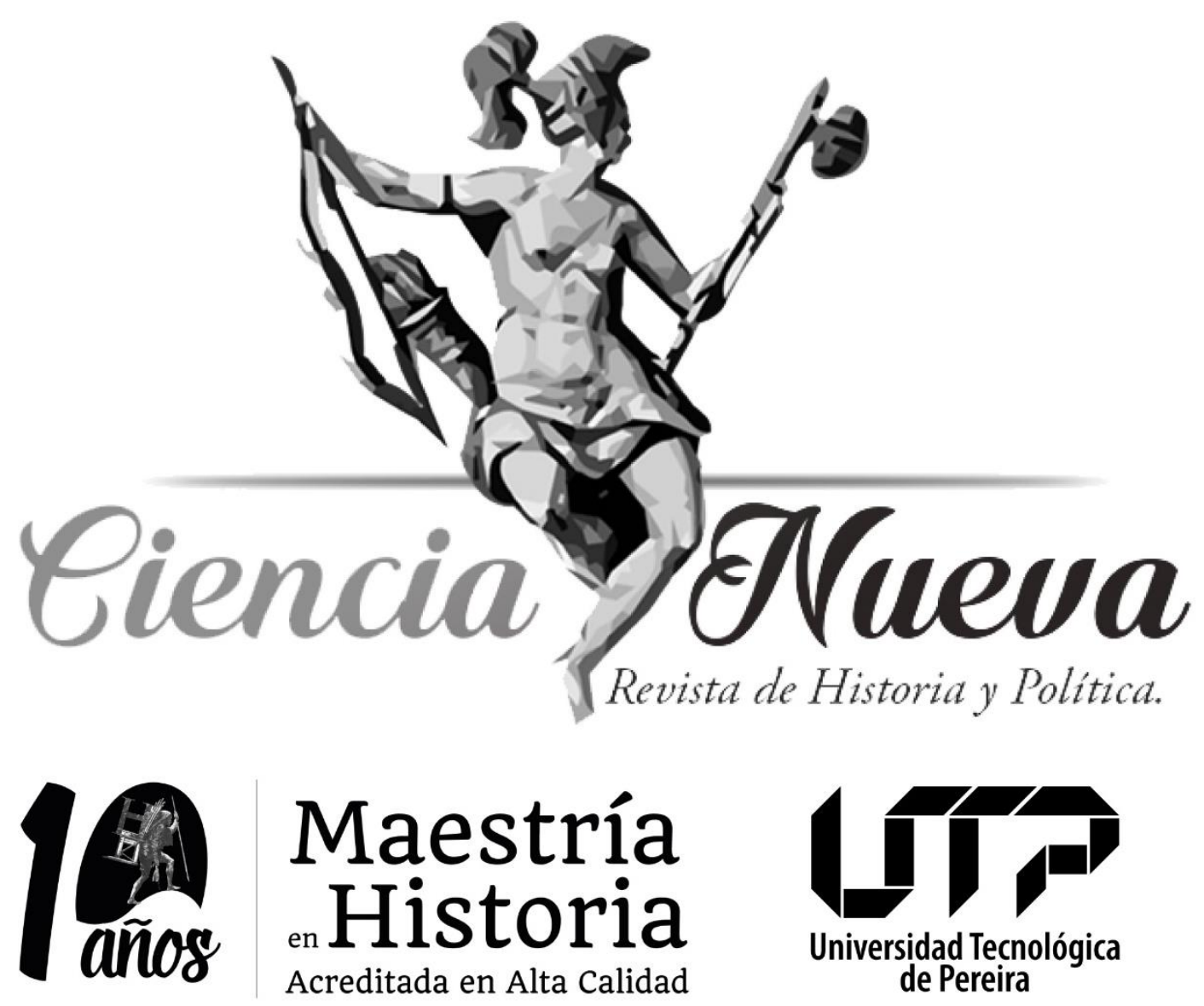

DOSSIER

\title{
LA REGIÓN DE SUMAPAZ Y LA GUERRA IRREGULAR EN COLOMBIA. VIOLENCIA POLÍTICA 1948-2008
}

THE SUMAPAZ REGION AND IRREGULAR WARFARE IN COLOMBIA. POLITICAL VIOLENCE 1948-2008 Wilson Rigoberto Pabón Quintero

pp. 133-149

DOI: https://doi.org/10.22517/25392662.24460

Vol. 4 Núm. 2 | Julio-diciembre de 2020

Pereira, Colombia

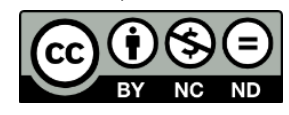




\title{
LA REGIÓN DE SUMAPAZ Y LA GUERRA IRREGULAR EN COLOMBIA. ViolenCia Política 1948-2008*
}

\author{
The Sumapaz REgion AND IRREgUlar WARFARE IN COLOMBIA. \\ Political ViOLENCE 1948-2008
}

Wilson Rigoberto Pabón Quintero** wilsonpq@hotmail.com

ORCID: https://orcid.org/0000-0002-3824-7936

\begin{tabular}{cl}
\hline Recibido: & 15 de enero de 2021. \\
Revisado: & 20 de febrero de 2020. \\
Aceptado: & 30 de noviembre de 2020. \\
Publicado: & 31 de diciembre de 2020. \\
\hline
\end{tabular}

\section{Resumen}

La región de Sumapaz ha sido foco de organizaciones campesinas y de movilización social. Las diversas violencias, al igual que los procesos de paz de los distintos momentos en Colombia, se han manifestado allí. Lo que ha marcado la memoria de sus habitantes y la ha convertido en referente de estudios locales-nacionales e incluso globales sobre estos temas. De esta manera, desde los años cincuenta con la contienda bipartidista, pasando por la violencia del Frente Nacional y el conflicto armado interno, se desarrollaron prácticas violentas que se enmarcan en estrategias de guerra irregular, tan característica de los enfrentamientos políticos a nivel mundial durante la Guerra Fría. Todos los actores armados utilizaron métodos no convencionales para atacar a sus enemigos, lo que hace que la violencia en Colombia se haya manifestado de forma macabra y sea un referente permanente en los recuerdos de sus habitantes. Así, el presente artículo pretende entender la manera en que se manifestó la guerra irregular en un caso emblemático en el país, la región de Sumapaz, como epicentro de prácticas virulentas por parte de actores armados legales e ilegales desde mitad del siglo XX.

Palabras clave: Colombia, Sumapaz, historia-memoria, violencia política, guerra irregular.

\footnotetext{
* Este documento respeta las directrices y normas dispuestas en la Declaración de Ética de Publicación de Ciencia Nueva, Revista de Historia y Política. Esta declaración puede consultarse en la página web de la revista: http://revistas.utp.edu.co/index.php/historia

** Historiador por la Universidad Nacional de Colombia; magíster en Ciencias Sociales de las Religiones por la École Pratique Des Hautes Études, Francia; candidato a doctor en Antropología y Sociología, Université Paris VII - Denis Diderot, Francia. Ha sido investigador y consultor en varios proyectos acerca de temas de memoria e historia y conflicto armado interno en Colombia, sobre los cuales versan sus publicaciones. Es miembro del Capítulo Bogotá de la Asociación Colombiana de Historiadores. Actualmente es docente-investigador de tiempo completo de la Facultad de Comunicación Social-Periodismo de la Universidad Externado de Colombia.
} 


\section{Abstract}

The Sumapaz region has been a center for peasant organizations and social mobilization. Simultaneously, different manifestations of the armed violence that takes place in Colombia and their multiple peace processes have impacted the region across time. This simultaneity of mobilization and violence has defined the history and memory of the habitants of this region making of this region a reference point for the understanding of the local, national even global dynamics between war and peace around Cold War. From the 1950's and within the framework of the bipartisan civil war, their aftermath with the consociationalist agreement of the Frente Nacional, and within the framework for the continuum of armed violence, violent repertoires have been deployed in this area. This has impacted the history and the memory of the inhabitants of this area. This article aims to understand the way in which this violence has taken place, and how irregular warfare emerged in the Sumapaz area.

Keywords: Colombia, Sumapaz, historical memory, political violence, irregular warfare.

\section{Introducción}

\section{Resume}

La région de Sumapaz a été la demeure des organisations paysannes et de la mobilisation sociale, de la même manière, les diverses violences ainsi que des processus de paix lors de plusieurs événements en Colombie qui se sont déroulés là et qui ont marqué la mémoire des habitants de cette région, sont devenus des thèmes de référence dans les études locales, nationales et même globales. De cette manière, depuis les années cinquante avec le conflit lié au bipartisme, qui évolue ensuite vers le Frente Nacional et sa violence, pour aboutir au conflit armé interne, se sont développées des pratiques violentes qui sont l'apanage des stratégies de guérilla, si caractéristiques des affrontements politiques au niveau mondial pendant la Guerre Froide. Tous les acteurs armés ont utilisé des méthodes non conventionnelles pour combattre leurs ennemis, ce qui fait que la violence en Colombie s'est manifestée de manière macabre et constitue une référence permanente dans la mémoire de ses habitants. Le présent article prétend ainsi expliquer la manière dont s'est manifestée la guerre irrégulière dans un cas emblématique pour le pays, la région de Sumapaz, épicentre de pratiques violentes de la part des acteurs armés, légaux et illégaux, depuis le milieu du XXème siècle.

Mots clés : Colombie, Sumapaz, histoiremémoire, violence politique, guerre irrégulière.

La guerra en Colombia ha marcado los destinos del país, hasta el punto de pensarse que su historia ha estado permeada por la violencia de cualquier tipo, además la memoria de sus habitantes la recuerda constantemente. Pero, adicional a esto, hay algo que hizo parte de los enfrentamientos de los diversos enemigos en estos conflictos, y fue la estrategia de guerra irregular que utilizaron los grupos enfrentados desde la década de los años cincuenta. Esto no es solo característico de las violencias en Colombia, pues la misma ya se utilizaba en otros continentes, pero sí marcó la forma de enfrentarse militarmente en el país, generando más víctimas dentro de una guerra de desgaste de varias décadas, lo que la convierte en una de las más viejas del hemisferio occidental.

Luego de la Segunda Guerra Mundial, los enfrentamientos entre las dos grandes potencias sucedieron de forma indirecta. Tanto los Estados Unidos como la Unión Soviética decidieron no entrar en un conflicto armado entre ellos, y se dedicaron a participar en guerras internas o a financiar grupos enemigos defendiendo sus intereses. Al terminar la guerra de 
Corea (1950-1953), que dividió este país en los dos sistemas predominantes, los enfrentamientos armados tomaron un cariz de guerra distinto al vivido durante la primera mitad del siglo XX. Los grandes ejércitos de las dos grandes conflagraciones mundiales ahora se difuminaron en pequeños grupos que, con la estrategia de la guerra de guerrillas, cambiaron la forma de asumir los combates.

La guerra de independencia de Argelia (1954-1962), el largo conflicto de Vietnam (1955-1975), la guerra de Afganistán (1978-1992) y la guerra civil angoleña (1975-2002) son claros ejemplos de este nuevo tipo de enfrentamientos, cuyas características principales son la guerra de desgaste y su alargamiento en el tiempo. A esto se debe añadir que las «nuevas guerras», como las llamó Herfried Münkler, tienen tintes globales, ponen de antemano los intereses económicos sobre los políticos, y han hecho que, en cierto sentido, se privatice la guerra $^{1}$. No obstante, para definir lo que se entiende por «guerra irregular» tendremos en cuenta lo planteado por el Derecho Internacional Humanitario (DIH) que, en tanto organismo supranacional, busca poner límites y normas a los conflictos armados. En este sentido, este tipo de estrategia de guerra contempla operaciones psicológicas y político-ideológicas, utilizadas tanto por los ejércitos regulares como por los grupos insurgentes ${ }^{2}$.

Para poder dar cuenta de la forma en que se manifestó este tipo de guerra en Colombia nos centraremos en una región tipo, en la cual este fenómeno fue recurrente, y así trataremos de dar pistas para la comprensión de un conflicto tan complejo como es el colombiano.

Ahora bien, algunas de las formas en que se enfrentaron los enemigos en el país, dentro de las varias violencias vividas desde hace más de setenta años, hizo que se utilizaran también civiles armados, lo que según algunos autores se debe clasificar dentro de la denominada «guerra sucia», que hace parte de la misma guerra irregular. Una de las regiones que ha sufrido este flagelo, pero que no ha sido conocida como una de las más violentas en Colombia fue la de Sumapaz, que colinda con la capital, Bogotá. Reconocida por la existencia de movimientos campesinos y de presencia de partidos de izquierda desde finales del siglo XIX, por lo que es catalogada inclusive como un espacio peligroso para los intereses nacionales desde los centros de poder, ya que se identifica como corredor estratégico para los grupos armados. De la misma forma, las guerrillas liberales y luego comunistas, de fuerte presencia en la región, han utilizado la estrategia de guerra de guerrillas, lo que obligó a sus contrincantes a usar tácticas de guerra irregular.

El presente escrito permite dar cuenta de la forma en que, durante los años comprendidos entre 1948 y 2008, los varios grupos armados de las distintas violencias han utilizado la «guerra sucia» dentro de la «guerra irregular» en Colombia. Esto porque sus acciones hacen parte de una estrategia en los conflictos, cuyo accionar es justificado por quienes se enfrentan, difiriendo de la guerra tradicional, en algunos casos, por la utilización también de civiles armados con fines tácticos u ofensivos ${ }^{3}$.

Para el análisis global del caso colombiano se tendrá en cuenta, en primer lugar, lo que Gonzalo Sánchez llama circularidad del conflicto, entendido como momentos no resueltos de violencia que engendran otros ${ }^{4}$. Por esto nos centraremos en tres periodos en

\footnotetext{
${ }^{1}$ Ver: Herfried Münkler, Viejas y nuevas guerras. Asimetría y privatización de la violencia (Madrid: Siglo XXI, 2005).

${ }^{2}$ Vilma Liliana Franco, «Guerra irregular: entre la política y el imperativo moral», Estudios Políticos, n. ${ }^{\circ} 19$, (2001): 40.

${ }^{3}$ Ver: Javier S. J. Giraldo, «Miradas desveladas sobre la guerra interna», abril de 2003, Bogotá, acceso el 12 de diciembre de 2018, https://www.javiergiraldo.org/spip.php?article17

${ }^{4}$ Ver: Gonzalo Sánchez, Guerras, memoria e historia (Bogotá: ICAHN, 2003).
} 
particular: La Violencia de los años cuarenta y cincuenta, también conocida como La Violencia con mayúscula, en la cual se hicieron célebres los denominados «chulavitas»; los años del Frente Nacional, de conformación de las guerrillas de corte socialista y, por otro lado, donde los dirigentes liberales y conservadores que, utilizando campesinos armados, intimidaron y asesinaron personas relacionándolas con el movimiento comunista internacional; y la violencia más reciente en la región, con el trasfondo de la lucha subversiva y de la guerra contra las drogas, que hizo movilizar sujetos pertenecientes a los grupos paramilitares de varias regiones del país hacia la zona de Sumapaz.

Esta región es compartida por los departamentos de Cundinamarca y Tolima, que se divide entre la montaña alta, con el páramo de Sumapaz; la montaña media, Arbeláez, Cabrera, Cunday, Fusagasugá, Icononzo, Pandi, Pasca, San Bernardo, Tibacuy, Venecia y Villarrica, de predominancia de la guerrilla de las FARC hasta su desmovilización; y el terreno plano, con los municipios de Carmen de Apicalá y Melgar, de presencia estatal y de control de la fuerza pública. Actualmente, en la vereda La Fila, del municipio de Icononzo (Tolima) se encuentra el Espacio Territorial de Capacitación y Reincorporación (ETCR) «Antonio Nariño», establecido allí luego de la firma del acuerdo de paz con el gobierno en 2016.

\section{La «guerra sucia» en La Violencia}

El período llamado de La Violencia propiamente, algunos investigadores lo hacen comenzar en 1948, mientras que otros lo delimitan desde 1946, prolongándose hasta 1965 aproximadamente. La magnitud de los hechos que se vivieron en ese período contribuyó a personificarlos hasta el punto de que, como advierte Carlos Ortiz citado por Gonzalo Sánchez, las gentes comenzaron a hablar de La Violencia como un Gran Sujeto Histórico, al que atribuían una acción casi demoníaca ${ }^{5}$.

Mariano Ospina Pérez es elegido nuevo presidente de la República y los conservadores retoman el mando del Estado en 1946. Posteriormente, los acontecimientos del 9 de abril de 1948, que terminaron mal llamándose «El Bogotazo»-ya que tuvieron repercusiones en todo el país y no solo en la capital-, le permitieron al gobierno y a los dirigentes de los partidos tradicionales afianzarse en el poder. A partir de este momento, los conservadores decidieron organizar una policía única que sirviera a sus intereses de «conservatizar» la nación colombiana bajo una política de «¡A sangre y fuego!», esta desde ahora se conocería como la Popol (policía política), limpiada por el Estado de representantes del liberalismo ${ }^{6}$. Adicionalmente, se reclutaron grupos de civiles conservadores para que actuaran a su lado, estos, ayudados por las fuerzas militares y de policía politizadas, fueron quienes terminaron llevando el terror a distintos rincones del país, época de violencia que se vivió en el país como una guerra civil no declarada.

La Dirección de la Policía Nacional se había propuesto asegurar al gobierno azul mediante la incorporación de personal tradicionalmente conservador de las zonas de Chiquinquirá, Boavita y La Uvita en el departamento de Boyacá, y de Vélez y García Rovira en Santander, provincias que en los años treinta habían sido azotadas por la persecución liberal que despojó de sus territorios a los conservadores y los hizo emigrar hacia otras

\footnotetext{
${ }^{5}$ Gonzalo Sánchez, «Los estudios sobre la Violencia. Balances y perspectivas», en Pasado y presente de la violencia en Colombia, comp. por Gonzalo Sánchez y Ricardo Peñaranda (Bogotá: La Carreta Editores, 2007), 22.

${ }^{6}$ Rocío Londoño y Medófilo Medina, «Eso también explica la muerte de Gaitán. Entrevista con José María Villarreal», Análisis Político, n. ${ }^{\circ} 38$ (septiembre/diciembre de 1999), 61.
} 
regiones del país ${ }^{7}$. Estos nuevos policías tenían entonces no solamente la orden de defender los intereses de su gobierno, sino, asimismo, la posibilidad de vengarse por la pérdida de sus tierras o la muerte de sus familiares a manos de liberales.

Los policías y civiles conservadores de los años de la hegemonía conservadora llevaron el apelativo de «chulavitas», nombre de la vereda de la cual eran originarios en el municipio de Boavita (Boyacá), los cuales tuvieron la fama de ser unos de los más sanguinarios de la época, porque «la noticia de que la muerte venía de camino vestida de policía, acompañada de civiles armados, llegaba tarde. Luego, después de la sorpresa, el dramático conteo de cuerpos inertes, las lágrimas y los gritos adoloridos de venganza ${ }^{8}$. Victimarios que dejaron las huellas de su presencia en la mente y el recuerdo de muchas personas y que, sin embargo, no actuaron solos.

Miembros del Ejército, la Policía y civiles conservadores sectarios realizaban visitas esporádicas a las veredas reconocidas como liberales en varios municipios, o establecían retenes en las carreteras demandando por los papeles de cada persona. Tras ser identificados como enemigos los llevaban a las cárceles, algunos eran torturados y, hacia la media noche, sacados y transportados en las volquetas municipales hacia diversos lugares que con el tiempo se hicieron famosos porque era allí donde muchos eran fusilados y luego arrojados a ríos o peñascos.

El Puente Natural de Pandi o Icononzo, en el caudal medio del río Sumapaz, fue el lugar en donde estos grupos de victimarios dieron rienda suelta a su poderío. Sus habitantes comentan que la costumbre de tirar los muertos desde este puente comenzó a principios de los años cincuenta y es un hecho que se ha repetido con el transcurrir de los años, por lo cual aún hoy es usual la advertencia: «No se acerque por allá, que de pronto lo botan».

Las personas que iban a ser arrojadas al río eran aprehendidas por los policías, quienes las llevaban a la cárcel y comenzaban a hacer correr el rumor de que estaban enfermas y había que trasladarlas al hospital. Pero los conservadores no aludían ciertamente al Hospital de Fusagasugá, el principal de la región, sino al «Hospital Sumapaz», una manera de llamar al río a cuyo cauce llegaron los cuerpos, a veces vivos aún, de muchos de los detenidos. Pedro Martín García, testigo de los hechos y habitante de Icononzo (Tolima), nos relata lo siguiente:

Comienza a haber muchas persecuciones, presos, personas presas y los traían a Icononzo, y la idea era matarlos. Entonces se sacaba un cuento de que la persona estaba enferma. Que trajeron de arriba, de por allá de una montaña, trajeron diez personas, pero que están todos enfermos, entonces hay que llevarlos al Hospital Sumapaz, había que llevarlos al hospital Sumapaz, entonces todo el mundo supo que había que llevarlos al Hospital Sumapaz. Allá, dizque los encerraban en el hospital, pero en el día parece que los inyectaban, no sabemos con qué cosas, les aplicaban, el hecho es que ya al atardecer ya estaban enfermos. Y luego, entonces, por la noche los metían en una volqueta, esa gente que estaba allí armada y todo eso, que eran los famosos chulavitas, entonces utilizaban los recursos del municipio que eran las volquetas del municipio. Entonces los montaban en esa volqueta y se iban hacia la media noche y los llevaban al Puente Natural. Ahí en el Puente Natural los ponían al borde del peñasco, del abismo y los iban echando de ahí para abajo, vivos, uno por uno, y todos eran liberales ${ }^{9}$.

\footnotetext{
${ }^{7}$ Carlos Miguel Ortiz, Estado y subversión en Colombia. La violencia en el Quindío años 50 (Bogotá: CEREC, 1985), 128.

${ }^{8}$ Arturo Alape, El Bogotazo, memorias del olvido (Bogotá: Planeta, 2000), 69.

${ }^{9}$ Entrevista con Pedro Martín García, profesor, grabación magnetofónica, Icononzo (Tolima), 27 de octubre de 1999. Tomado de Wilson Pabón. La muerte y los muertos en Colombia. Violencia política, víctimas y victimarios (Bogotá: FUAC, 2015), 86-87.
} 
La sensación que dejan los relatos de los habitantes de la región es como si durante los años cuarenta y cincuenta el río Sumapaz hubiera dejado de llevar agua en sus cauces y prácticamente conducía sangre y una maraña de cuerpos sin movimiento, que no dejaban entrever ningún asomo de agua a consecuencia de todos los cadáveres arrojados durante La Violencia.

La utilización de civiles armados, sumada a la estrategia de guerra sin cuartel contra los liberales de la región de Sumapaz, hizo que algunos campesinos se armaran como grupos de autodefensa. El paso siguiente fue el de convertirse en guerrillas liberales, las que, junto a las de los Llanos, tuvieron como objetivo final la toma del poder para el Partido Liberal. A partir de la llegada de la dictadura del general Gustavo Rojas Pinilla (1953-1957), se buscó lograr un fin pactado de la guerra, lo que permitió la entrega de armas por parte de estas guerrillas. Pero el conflicto continuaría, puesto que el ejército colombiano luego de su participación en la guerra de Corea no sería el mismo, ya que a partir de allí se convirtió en una institución antisubversiva, que enfrentaría al comunismo en todas sus formas ${ }^{10}$.

De allí que en 1955 se haya desarrollado en la región la conocida guerra de Villarrica o guerra de Sumapaz, puesto que la zona se convirtió en un laboratorio de la Guerra Fría, donde se utilizaron las bombas que luego los estadounidenses arrojarían sobre Vietnam ${ }^{11}$; además de todas las prácticas contrainsurgentes globalizadas, como las utilizadas por los franceses en Argelia, y que fueron consignadas por David Galula, teórico francés de la contrainsurrección ${ }^{12}$, lo que marcó las memorias de los sumapaceños, que identifican estos años con la muerte y el desplazamiento ${ }^{13}$.

\section{El Frente Nacional y la Guerra Fría}

Aprovechando el contexto de ofensiva militar que el Estado decretó hacia las guerrillas liberales, sumado a todos los estragos generados por la violencia bipartidista, los dirigentes del Partido Liberal y del Partido Conservador firmaron un pacto que les permitía intercalarse en el poder durante los siguientes dieciséis años, en el periodo del Frente Nacional (1958-1974). Esta alianza limitó la participación de los diversos grupos políticos existentes en el país que, además, se convirtieron en el objetivo de una campaña de hostigamiento, persecución y retaliación, porque disentían del oficialismo, durante lo que se conoció como la «guerra selectiva del frentenacionalismo» ${ }^{14}$. En estos años, la violencia se manifestó de manera directa por parte de liberales y conservadores en contra de los representantes de movimientos campesinos y populares, relacionándolos con el comunismo. La unión del bipartidismo buscando «la salvaguarda de la democracia» generó, así mismo, muchas muertes que engrosaron la lista de las víctimas irreconocibles de los diferentes conflictos políticos en el país.

\footnotetext{
${ }^{10}$ Ver: Mario Aguilera Peña, Las Farc: la guerrilla campesina, 1949-2010, ¿ideas circulares en un mundo cambiante?, actores armados y población civil (Bogotá: ASDI, Organización Internacional para las Migraciones, 2010).

${ }^{11}$ Ver: Jacques Aprile-Gniset, La crónica de Villarrica (Bogotá: Ediciones Antropos, 1991).

${ }^{12}$ David Galula, Contre-insurrection : théorie et pratique (Paris : Economica, 2008).

${ }^{13}$ Entrevista a Emelina Parra Rodríguez, 7 de junio de 2018, Cunday (Tolima).

${ }^{14}$ José Jairo González y Elsy Marulanda, Historias de frontera. Colonización y guerras en el Sumapaz (Bogotá: CINEP, 1990), 40-41.
} 
Esta violencia se sintió principalmente en la región de Sumapaz ${ }^{15}$. Antonio Vargas Roa, autodenominado liberal «limpio», hacendado y jefe de su partido en esta zona, tuvo su centro de actividades en los municipios de Pandi e Icononzo, y ordenó el asesinato de algunas personas bajo la premisa de una política de «limpieza de la región» en contra de los grupos de comunistas, de dirigentes sociales y de liberales «comunes», llamados así por tener tendencias socialistas. Muchas de sus víctimas terminaron flotando en las aguas del río Sumapaz y sus cuerpos encontrados luego de varios días, con señales de tortura y en estado de descomposición, atascados en las piedras de La Azufrada, sitio turístico muy pedregoso donde se detenían los cadáveres arrojados desde el Puente Natural.

Teniendo en cuenta la información divulgada en la prensa y en comunicados, el Comité de Solidaridad con los Presos Políticos, en 1974, publicó El libro negro de la represión. Frente Nacional 1958-1974 ${ }^{16}$, en el cual se relatan, de maneras a veces crueles pero explícitas, la forma en que fueron asesinadas y torturadas varias de las víctimas de la represión liberal-conservadora.

En las décadas inmediatamente posteriores a La Violencia fueron recurrentes los casos en que personas eran contratadas por políticos y terratenientes para que trabajaran para ellos como matones a sueldo. De esta forma, para el primer año se contaban 20 asesinatos individuales cometidos por estos siniestros personajes en varias zonas de la región de Sumapaz. Por ejemplo, en septiembre de 1959, durante una fiesta campesina en el municipio de Icononzo (Tolima), fueron asesinadas 3 personas y varias quedaron heridas, luego de que la policía abriera fuego para dispersar la reunión. Igualmente, en julio de 1960 fue encontrado muerto el concejal Antonio Fino en el municipio de Villarrica (Tolima), quien había sido elegido representando al partido liberal, pero era reconocido como un viejo luchador de la causa agraria en la región ${ }^{17}$. No se conocen los motivos exactos de estas acciones, pero las revoluciones en el mundo y la formación de guerrillas comunistas en los años sesenta hizo que se incluyera en las leyes colombianas una prohibición a las reuniones públicas sin previo permiso de las alcaldías o de las comisarías de policía.

Juan de la Cruz Varela (1902-1984), líder campesino y político de la región de Sumapaz, quien fue miembro de la UNIR de Jorge Eliécer Gaitán y desde 1950 del Partido Comunista, en esta época fue víctima de varios atentados en contra de su vida. En febrero de 1960 sufrió una tentativa de homicidio en la capital, en la que resultó herido por bala su hijo Teodosio Varela, quien dijo: «Es un plan de violencia oficial contra el pueblo» ${ }^{18}$. Luego, en septiembre del mismo año, fueron asesinados sus hermanos en el departamento del Meta, al igual que seis campesinos más, a manos de varios hombres fuertemente armados. Incluso en febrero de 1962, Varela fue apuñaleado en Bogotá sin consecuencias graves. Algunos

\footnotetext{
${ }^{15}$ Sobre la violencia en la región de Sumapaz existen algunos escritos. La principal estudiosa de la región es la profesora Rocío Londoño, quien ha publicado, entre otros: «Los nuevos hacendados de la provincia del Sumapaz (1890-1930)», en Territorios, regiones, sociedades, ed. por Renán Silva (Bogotá: Universidad del Valle, Fondo Editorial CEREC, 1994); Reseña crítica de la bibliografía de referencia sobre la región del Sumapaz (Bogotá, 25 de mayo 1997); y su último texto, su tesis doctoral en Historia, «Juan de la Cruz Varela. Región de Sumapaz, 1902-1984» (tesis doctoral, Universidad Nacional, Bogotá, 2012); fue igualmente coautora, junto con José Jairo González y Elsy Marulanda de Historias de frontera. Colonización y guerras en el Sumapaz (Bogotá: CINEP, 1990); y, por otro lado, el texto de Elsy Marulanda, Colonización y conflicto. Las lecciones del Sumapaz (Bogotá: Tercer Mundo Editores, IEPRI-UN, 1991).

${ }^{16}$ Comité de Solidaridad con los Presos Políticos, El libro negro de la represión. Frente Nacional 1958-1974, (Bogotá: Editorial Gráficas Mundo Nuevo, 1974).

${ }^{17}$ Comité de Solidaridad con los Presos Políticos, El libro negro de la represión..., 22.

${ }^{18}$ Comité de Solidaridad con los Presos Políticos, El libro negro de la represión..., 23.
} 
habitantes de Sumapaz se sienten muy orgullosos de saber que este dirigente finalizó sus días de muerte natural, luego de múltiples intentos fallidos de homicidio en su contra, con lo que se le dio un duro golpe al Estado, que lo buscó para liquidarlo, pero al final no lo consiguió ${ }^{19}$.

En marzo de 1961, Antonio Torres, latifundista del municipio de Pandi, ofreció públicamente dos mil pesos por cada uno de los dirigentes agrarios de la zona de Sumapaz para que fueran eliminados. Después, en abril, fue asesinado Genaro Fernández, último sobreviviente de una familia campesina del municipio de Villarrica (Tolima), exterminada poco a poco por matones a sueldo, debido a que no habían querido ceder su finca ni abandonar la región; otro de los trasfondos de la violencia política manifestado en la lucha por la tierra ${ }^{20}$. También, en mayo, fue muerto Miguel Alfonso Rodríguez en Icononzo (Tolima), antiguo guerrillero de las autodefensas campesinas, a manos de alias Resortes, quien aparentemente era contratado regularmente por los terratenientes de la zona ${ }^{21}$.

Posteriormente, en Pandi (Cundinamarca) en junio de 1962, Antonio Vargas Roa comandó el asesinato del dirigente agrario Tulio Martínez Rodríguez. El mismo año, los asesinos al mando de Vargas Roa publicaron y pegaron en todas las esquinas del municipio una lista en la que aparecían los nombres de cincuenta dirigentes campesinos de la región que serían eliminados, diez de ellos ya lo habían sido por lo que aparecían tachados en esta triste relación ${ }^{22}$.

Esta violencia desde los partidos tradicionales ha tratado de ocultarse por varias razones: la primera, es que los asesinatos fueron selectivos y constantes, pero no se pueden comparar en número con las altas cifras de muertos de los años cuarenta y cincuenta o de los noventa y dos mil a nivel nacional; en segundo lugar, el periodo del Frente Nacional siempre ha sido presentado de forma oficial como pacífico porque ese fue uno de los objetivos de su implementación, adicional a esto la falta de estudios sobre este periodo en relación con la violencia hace que se deba entender mucho más, pues su análisis permitirá dar cuenta de esa espiral de violencia que azota al país aún en la actualidad, lo mismo que de las relaciones entre uno y otro período para entender las dinámicas y posibles respuestas que permitan llegar a un fin pacífico real del conflicto.

\section{Las guerrillas y la guerra irregular}

Una de las principales características de los grupos subversivos es su estilo de hacer la guerra. Desde su formación, una guerrilla como las FARC, de presencia casi permanente en la región de Sumapaz, utilizó la estrategia de la guerra de guerrillas, tan característica de los conflictos durante los años de la Guerra Fría.

Esta guerrilla hace parte de la historia de Sumapaz, inclusive uno de sus más cuestionados líderes, debido a sus crueles acciones militares, Víctor Julio Suárez Rojas, alias Jorge Briceño Suárez o Mono Jojoy, nació en Cabrera (Cundinamarca) el 2 de enero de 1953. Los mitos fundacionales de dicha guerrilla recuerdan los ataques por parte del gobierno del general Gustavo Rojas Pinilla a las autodefensas liberales establecidas allí durante la guerra de Villarrica, estas con el tiempo se convertirían al comunismo. Pese a esto, posteriormente, sus acciones violentas y excesos terminaron por transformar su apoyo social y político en el rechazo a su presencia por parte de algunos habitantes, durante las últimas décadas.

\footnotetext{
${ }^{19}$ Ver: Londoño, «Juan de la Cruz Varela: sociedad y política en la región de Sumapaz (1902-1984)».

${ }^{20}$ Ver: Centro Nacional de Memoria Histórica, ¡Basta ya! Colombia: Memorias de guerra y dignidad (Bogotá: Imprenta Nacional, 2013).

${ }^{21}$ Comité de Solidaridad con los Presos Políticos, El libro negro de la represión ..., 27.

${ }^{22}$ Comité de Solidaridad con los Presos Políticos, El libro negro de la represión..., 34.
} 
Ahora bien, no pretendemos contar aquí la historia de las FARC, pero sí dar cuenta de cómo la misma está ligada a la tradición de guerra irregular en Colombia. Después de la Segunda Guerra Mundial, las guerras de independencia de aquellas regiones que no lograron la descolonización y creación de sus naciones-estado de forma pacífica, acudieron a un tipo de guerra que caracterizará las mismas que se tendrán desde los años cincuenta. Tomar como forma de lucha la guerra de guerrillas era menos costoso y más efectivo para las colonias enfrentadas a las grandes potencias europeas, venidas a menos a consecuencia de los costos sociales, políticos y económicos de las guerras mundiales.

La guerra de Corea, en la que participó el Batallón Colombia con 5.100 soldados, le permitió al ejército colombiano hacer parte de un conflicto internacional a gran escala, luchar codo a codo con grandes armadas y traer la idea de modernización de las Fuerzas Armadas al país de la mano de los Estados Unidos ${ }^{23}$. No obstante, los conflictos en Indochina, que serán el germen de la Guerra de Vietnam se caracterizarán por la guerra de guerrillas. Allí, los franceses utilizaron soldados árabes y negros de sus colonias africanas, quienes aprendieron de qué forma la guerra irregular es desgastante para los ejércitos coloniales, llevando esta manera de luchar a sus países durante sus guerras de independencia.

Teniendo en cuenta la victoria de la Revolución Cubana en 1959, sumado a las existentes guerrillas liberales en el Tolima y su conversión al comunismo, las guerrillas en Colombia tomaron la guerra de desgaste como estrategia para la toma del poder. Las condiciones mismas de hombres y armas de estos grupos insurgentes, lo mismo que las experiencias e influencias extranjeras, sumergieron al país en décadas de conflicto de guerra irregular y miles de víctimas.

Durante las décadas de los años setenta y ochenta el accionar de las FARC en Sumapaz es latente, y la falta de presencia del Estado en los municipios que hacen parte de ella permitió que este grupo se convirtiera en un estado paralelo, brindando seguridad, realizando acciones judiciales y de policía, lo mismo que cobrando impuestos para su financiación.

Pero, la estrategia de este movimiento a partir de su VII conferencia en mayo de 1982 fue apostarle a la conformación de un ejército revolucionario, añadiéndole las siglas EP (Ejército del Pueblo) a su nombre. Esto hizo que su crecimiento en número de hombres y frentes fuera exponencial durante la década de los años ochenta, hasta que en los noventa aumentó su presencia en varias regiones. Por esta y otras razones, son estos años y, por ende, los dos mil, los más violentos del conflicto armado interno colombiano; lo que se ve traducido en Sumapaz en «una ampliación de su presencia en el territorio y en un incremento de los hostigamientos, emboscadas y los actos terroristas» ${ }^{24}$. Esto expresado en «el alto nivel de ataques a instalaciones de la fuerza pública; el número de alcaldes amenazados que no despachaban desde sus municipios por amenazas contra sus vidas; el aumento de exacciones y secuestro a empresarios, comerciantes, agricultores y ganaderos» ${ }^{25}$. Como en el caso de

\footnotetext{
${ }^{23}$ Ver: Saúl Rodríguez, La influencia de los Estados Unidos en el Ejército colombiano 1951-1959 (Medellín: La Carreta Editores, 2006).

${ }^{24}$ Camilo Echandía, «El conflicto armado colombiano en los años noventa: cambios en las estrategias y efectos económicos», Revista Colombia Internacional 49 (2000): 121.

${ }_{25}$ Tribunal Superior del Distrito Judicial de Bogotá, Sala de Justicia y Paz, «Sentencia de Jhon Fredy Rubio Sierra y otros exintegrantes del Bloque Tolima», mayo 19 de 2014, p. 134. Referenciado en Cita 57 p. 159 de Centro Nacional de Memoria Histórica, De los grupos precursores al Bloque Tolima (AUC) (Bogotá: Imprenta Nacional, 2017).
} 
Carlos Alberto Trujillo Vaquero, exalcalde de Cunday (Tolima), quien fue secuestrado durante 25 días por las FARC ${ }^{26}$.

Con esto último se demuestra que no solamente los enemigos declarados de la guerrilla eran las instituciones del Estado y sus representantes, sino que también sus acciones se dirigieron hacia civiles, debido a su necesidad de financiación. Un problema adicional fue que llegaron a cobrar, «vacunas», como era llamado su impuesto revolucionario, inclusive a personas que tenían puestos de venta ambulantes, lo que evidentemente fue minando su relación con la población civil.

Otro elemento fundamental para que las FARC perdieran apoyo social en Sumapaz fue la utilización de los llamados «milicianos», quienes eran hombres contratados por la guerrilla para que hicieran las veces de informantes y cobradores de impuestos en las cabeceras municipales. Estos eran jóvenes desempleados o pequeños delincuentes, contratados en bares, billares y prostíbulos. Fueron muy criticados por sus excesos en las regiones al no tener ese vínculo político tan fuerte como el que se cargaban los «viejos guerrilleros» ${ }^{27}$. Como en el caso de Villarrica (Tolima), donde como lo manifiestan sus habitantes: «nosotros convivíamos con ellos, pero comenzaron a matar un poco de gente. Fue grave la cuestión aquí» $^{28}$. Las guerrillas en su estrategia de desgaste del establecimiento acudieron a civiles armados, y junto a sus acciones violentas y de guerra irregular erosionaron su imagen política revolucionaria. Esto tuvo eco en los grandes medios de comunicación, que los mostraron como grupos narcoterroristas sin un objetivo revolucionario real ${ }^{29}$.

\section{El paramilitarismo en Sumapaz}

Las autodenominadas Autodefensas Campesinas aparecieron en el ámbito nacional a finales de los años setenta. Su presencia hace parte de la confrontación entre el Estado y las guerrillas en Colombia, y su accionar lo incluiremos dentro de lo que se conoce como «guerra sucia». El recurrir a civiles armados ha sido una de las características de los ejércitos de finales del siglo XX, estos son reclutados de la masa de desempleados, desesperanzados y subempleados que encuentran en el delito una forma de vida, buscando operar contra determinados grupos o individuos. El concepto de «paramilitar» es frecuentemente empleado, pero no tiene un sentido muy claro. En Colombia fueron el fruto de autodefensas, creadas y financiadas por algunos ganaderos para luchar en contra de la guerrilla, o incluso armadas y entrenadas por el Estado como combatientes irregulares para el mismo fin. Tienen un paralelo con las Rondas Campesinas del Perú y, de hecho, la Defensoría del Pueblo oficina gubernamental colombiana creada con la nueva constitución de 1991-, las clasificó como «fuerza alzada en armas y combatientes» y las convocó para recibir instrucción sobre la humanización del conflicto y el respeto a los derechos humanos ${ }^{30}$.

El historiador Carlos Medina Gallego estudió a los grupos paramilitares que se formaron en la región del Magdalena Medio a finales de los años setenta, siendo estas las

\footnotetext{
${ }^{26}$ Entrevista a Carlos Alberto Trujillo Vaquero, 7 de junio de 2018, Cunday (Tolima).

${ }^{27}$ Entrevista a Jorge Andrés Ortegón, varias, Icononzo (Tolima). Al respecto se puede consultar: Centro Nacional de Memoria Histórica, Guerrilla y población civil. Trayectoria de las FARC 1949-2013 (Bogotá: Imprenta Nacional, 2014).

${ }^{28}$ Entrevista a Aldemar Lozano Padilla, 27 de marzo de 2018, Villarrica (Tolima).

${ }^{29}$ Rubén Darío Zapata, «Los medios masivos y el conflicto en Colombia», Pueblos, n. ${ }^{\circ}$ (junio 2010), http://www.revistapueblos.org/blog/2010/07/12/los-medios-masivos-y-el-conflicto-en-colombia/

${ }^{30}$ Hermes Tovar, «Colonialismo, diversidad e intolerancia: la responsabilidad del historiador», en Pensar el pasado, ed. por Carlos Miguel Ortiz Sarmiento y Bernardo Tovar Zambrano (Bogotá: AGN, UN, 1997), 33.
} 
agrupaciones primigenias en Colombia. En un comienzo recibían un salario mensual y acompañaban al ejército en los allanamientos, detenciones y en los enfrentamientos con la guerrilla ${ }^{31}$. Posteriormente, comenzaron a trabajar para el narcotráfico, y este se convirtió en su principal fuente de financiación, con lo cual, además de profesar la doctrina de la Seguridad Nacional, se convirtieron en lo que algunos autores llaman «narcoparamilitares ${ }^{32}$.

Su crecimiento fue exponencial, y durante los años noventa fueron protagonistas de la violencia en Colombia sembrando el terror realizando desapariciones forzadas, torturando y asesinando. Las ACCU (Autodefensas Campesinas de Córdoba y Urabá) lideradas por Carlos Castaño, integrantes de las AUC (Autodefensas Unidas de Colombia), estaban conformadas en 1997 por cinco bloques con veinte frentes, que actuaban principalmente en las regiones de Urabá, el oriente y occidente antioqueño, la Costa Atlántica, el sur de Bolívar y en la zona minera cundiboyacense, creciendo día a día y desplazándose hacia otras zonas del país ${ }^{33}$. Luego, los paramilitares tomaron una gran fuerza al interior del país, debido a sus acciones militares, hasta el punto de que comenzaron a solicitar espacios políticos legítimos como tercer actor en el conflicto interno colombiano.

En un principio sus principales enemigos eran los grupos guerrilleros, sin embargo, entre sus víctimas se contaban de la misma manera: las organizaciones sindicales, campesinas y populares, como la CUT (Central Unitaria de Trabajadores), fundada en 1986, de la cual estos victimarios asesinaron a 116 de sus miembros y desaparecieron a 8 durante su primer año de funcionamiento ${ }^{34}$; los movimientos políticos de izquierda y los civiles acusados de colaboradores de las guerrillas ${ }^{35}$. Durante las tres últimas décadas sus acciones se dirigieron también contra quienes investigaron sobre las muertes que estos habían cometido, bien fueran los jueces o los familiares de las víctimas que demandaban justicia ${ }^{36}$, y en los últimos años hacia los llamados líderes sociales, entendidos como personas que trabajan por la defensa de los intereses de las comunidades en las que viven.

La Ley 975 de 2005 buscó, entre otras cosas, la reinserción de representantes de los grupos armados al margen de la ley, esta generó la entrega de un gran número de

\footnotetext{
${ }^{31}$ Carlos Medina, Autodefensas, paramilitares y narcotráfico en Colombia. Origen, desarrollo y consolidación. El caso "Puerto Boyacá” (Bogotá: Editorial Documentos Periodísticos, 1990), 184.

32 Ver: Fernando Cubides, «Narcotráfico y paramilitarismo: ¿un matrimonio indisoluble?», en El poder paramilitar, Alfredo Rangel (Bogotá: Planeta, 2005).

${ }^{33}$ Las ACCU estaban organizadas en 1997 bajo el mando general de un Estado Mayor, del cual se desprendían cinco bloques con sus respectivos frentes, así: 1. El Bloque Metro, con seis frentes, en el Eje Cafetero, el oriente antioqueño, el suroeste antioqueño, el Chocó, el occidente antioqueño y Río Grande; 2. El Bloque Urabá, con tres frentes en el Eje Cafetero, el Darién y el Atrato; 3. El Bloque Norte con seis frentes, en Sucre, Guajira, Bolívar, Atlántico, Magdalena y Cesar; 4. El Bloque Central con dos frentes, el nordeste y el sur de Bolívar; y 5. El Bloque Minero, con tres frentes en Ituango, Tarazá y San Jorge. «Los paras ganan la guerra», La Nota Económica, n. ${ }^{\circ} 4$ (17 de noviembre de 1997): 24-28.

${ }^{34}$ Amnesty International, Colombie : Droits de l'homme question d'urgence (Paris : Editions Francophones d'Amnesty International, 1988), 49.

${ }^{35}$ Medina, Autodefensas, Paramilitares y Narcotráfico en Colombia..., 15.

36 «Desde 1988, cada vez hay más víctimas civiles, sobre todo en el campo, "desaparecidos" o asesinatos políticos en el cuadro de campañas de lucha contra la guerrilla. Algunas son escogidas al azar, otras hacen parte de una selección precisa. En las zonas donde la guerrilla es muy activa, la ejecución de masacres, "desapariciones" y otras atrocidades es siempre confiada a las unidades paramilitares. Recurrir a estos grupos es hoy un principio fundamental de la estrategia antinsurreccional del ejército». Amnesty International, Colombie, Arrêtez les Massacres ! (Paris : Editions Francophones d'Amnesty International, 1988 ), 11. [Traducción del autor].
} 
paramilitares, quienes deberían dejar las armas. Las penas que pagarían en la cárcel oscilaban entre los cinco y ocho años, dependiendo de sus acciones y participación en delitos comunes o de violación de derechos humanos. Su inclusión en la Ley de Justicia y Paz dependería de las confesiones que realizaran, en las cuales debían hablar acerca de la estructura organizativa de sus grupos, los mismo que de su financiación y, algo que buscaba resarcir a las víctimas, la ubicación de fosas comunes o de los cuerpos de desaparecidos por sus acciones violentas ${ }^{37}$. Esta Ley fue muy criticada, algunos de estos individuos siguieron delinquiendo desde las cárceles o en las regiones, recibían las ayudas del Gobierno, e incluso algunos terminaron perteneciendo a otros grupos ilegales. Por esta razón, aparecen unas nuevas organizaciones denominadas por el Gobierno y los medios de comunicación como Bandas Criminales Emergentes (Bacrim) o Grupos Armados Organizados (GAO), que continúan defendiendo los intereses de políticos, ganaderos, hacendados y del narcotráfico, y que, si bien ya no son grandes estructuras militares, siguen con la ideología y organización paramilitar.

Así es como en los municipios de Colombia, cuando se escuchaban acercarse los motores de camionetas con vidrios polarizados, que generalmente no tenían placas que los identificaran, las noticias no parecían ser muy alentadoras. En su interior llevaban decenas de hombres que tenían como particularidad los pasamontañas que ocultaban sus rostros y las armas que portaban. Convocaban a todos los pobladores en el parque principal y llamaban por lista a quienes serían habitantes permanentes del pequeño cementerio que creció en un solo día. Sus cuerpos inertes y descuartizados debían ser enterrados por sus familiares.

Estos grupos tuvieron presencia en varios lugares, sobre todo con acciones violentas puntuales. Además, su accionar se presentó principalmente en algunos municipios de Cundinamarca, tales como: Cabrera, Venecia, Pandi, Fusagasugá, Tibacuy, Silvania, Granada y los límites entre Fusagasugá y Arbeláez. Por los lados del Tolima, los municipios de Icononzo, Cunday y Melgar, que fueron claves para las acciones de estos grupos en la región, principalmente por su característica de pueblos fronterizos.

El grupo paramilitar predominante en la región fue el denominado Bloque Tolima de las AUC, que fue consecuencia del desmonte de las Convivir en 1997, y la posterior integración de algunos de sus miembros a los grupos dirigidos por Carlos Castaño ${ }^{38}$. Como se menciona en el informe del Centro Nacional de Memoria Histórica: «Esta última etapa de conformación del Bloque significó la puesta en marcha de una maquinaria violenta, que combinaba la experticia bélica de quienes se habían formado en el contexto del conflicto histórico del sur del Tolima, y los métodos de violencia extrema ejecutados por las AUC. En este fenómeno tuvieron un papel determinante procesos del interior del grupo armado cuyo análisis contribuye a la comprensión de lo que significó el Bloque Tolima de las AUC» ${ }^{39}$.

La persecución y el asesinato de líderes sociales en Sumapaz por parte de grupos paramilitares ocurrieron durante los años comprendidos entre 1999 y 2008, aumentando en intensidad a partir del 2003. El fenómeno paramilitar fue apoyado por algún sector de la población con complicidad de las Fuerzas Armadas. Esto lo demuestra la primera masacre que realizaron en la región, que se dio en el municipio de Icononzo (Tolima), entre las 7:00 y 8:00 de la noche del 1 de abril del 2000. En esta fueron asesinadas cinco personas frente al cementerio que se encuentra a las afueras de la cabecera municipal. La principal víctima fue

\footnotetext{
${ }^{37}$ Ver: Ley 975 de 2005 o de Justicia y Paz.

${ }^{38}$ Centro Nacional de Memoria Histórica, De los grupos precursores al Bloque Tolima (AUC)..., 109.

${ }^{39}$ Centro Nacional de Memoria Histórica, De los grupos precursores al Bloque Tolima (AUC)..., 109.
} 
Johana Alejandra Yepes, hija del exalcalde del pueblo y presidenta del Concejo. Antes de marcharse, se hicieron los primeros grafitis en las paredes con las iniciales de las AUC.

Ricaurte Soria Ortiz alias 'Carlos Orlando', exintegrante del Bloque Tolima, aceptó su participación en esta masacre dentro del proceso de Justicia y Paz y dijo que para ello contaron con colaboración de la Fuerza Pública. Según ha documentado el centro de investigación académica Cinep, la Fuerza Pública que estaba establecida en Icononzo simuló enfrentar a los paras durante la matanza. Por estos hechos, el mayor del Ejército Edward Alberto Suárez Cuadros fue capturado en junio de 2013 por orden del Tribunal Superior de Ibagué ${ }^{40}$.

Las dinámicas de implementación de las acciones de estos grupos en la región se dieron de dos formas, según el CNMH: «Una de anclaje originario en la zona montañosa, de presencia histórica guerrillera, y los grupos paramilitares con anclaje inestable en las zonas planas, más con dinámicas de control y regulación que con repertorios de alta violencia» ${ }^{41}$.

El fenómeno del paramilitarismo en la región de Sumapaz generó asesinatos, desplazamiento forzado, amenazas, atentados, y todo lo que se relaciona con su modus operandi. Aquí cometieron 6 homicidios en Cunday en el año 2004; en Icononzo 4 en 2003 y 8 en 2004; y en Melgar 3 en 2004 ${ }^{42}$.

Los habitantes de varias veredas de Icononzo y Pandi, sobre todo aquellas que limitan con el río Sumapaz, fueron testigos de saqueos a tiendas comunitarias, incendios de hogares, torturas y, por supuesto, de asesinatos a personas de la región; o inclusive de algunos que fueron traídos de otras zonas para ser asesinados allí. El lugar privilegiado de ejecución fue nuevamente el Puente Natural, donde en muchas ocasiones se hicieron rituales de tortura y ejecución, como relató José Achury, quien habitaba a pocos metros del puente, en donde se escucha todo lo que sucede en este lugar:

Aquí en el Puente, el 28 de diciembre de 2003 mataron a 10 ahí, y los traían eran los paramilitares en esas camionetas, vidrios opacos y toda esa vaina. Cada vez que mataban a uno soltaban esas ráfagas de ametralladora, yo estaba acá, pero tenía a mi mamá muriéndose. [...] Mi amigo estaba preparado para ir al combate, pa' echar bala, pero él no estaba preparado para oír esos lamentos: ‘¡Ay, no me maten!', ‘¡ay, no me quiten el brazo!' Porque creo que a la señora le quitaron los senos, las piernas y todo. Porque ahí se oía, se oía cuando daban órdenes, porque ellos traían un megáfono, y traían exploradoras y planta eléctrica y hasta el carajo. Y eran los paramilitares, esos venían de allá del lado de Pandi ${ }^{43}$.

Un trasfondo que permitió asimismo la presencia de estos grupos ilegales en Sumapaz fue la política de Seguridad Democrática del gobierno de Álvaro Uribe Vélez (2002-2010), que buscaba a toda costa mostrar resultados a nivel nacional por parte del Estado en contra de las guerrillas. Fue así como en el municipio de Icononzo en junio de 2004, la Fuerza Pública, por intermedio del gobernador del Tolima, Jorge García Orjuela (exalcalde también de Icononzo para el periodo 2016-1019), lo mismo que el alcalde de esa época, Jesús Ignacio Jiménez, obsequiaron celulares con el cifrado 31078143-- a los presidentes de las Juntas de Acción Comunal (JAC) y demás líderes del municipio, así se comprometió a los campesinos con la función de informantes. Un caso que aclara lo anterior fue el del presidente de la JAC

\footnotetext{
40 «Aunque el tiempo pasa, a diario recuerdo ese momento», El Nuevo Día, Ibagué (2 de abril de 2015).

${ }^{41}$ Centro Nacional de Memoria Histórica, De los grupos precursores al Bloque Tolima (AUC)..., 240.

${ }^{42}$ Centro Nacional de Memoria Histórica, De los grupos precursores al Bloque Tolima (AUC)..., 243.

43 Entrevista a José Achury (q.e.p.d.), 8 de junio de 2018, Vereda El Chaparro, Icononzo (Tolima). [Transcripción: Evans Gama].
} 
Vereda El Triunfo, quien mencionó: «Cuando hay algo extraño de una vez se llamaba a la Brigada y al momentico llegaban los helicópteros, y a volar gallera ${ }^{44}$.

El 15 de septiembre de 2004, se realizó el paro agrario del suroriente del Tolima, que incluyó los municipios de Dolores, Alpujarra, Prado e Icononzo. El Ejército y la Policía impidieron la marcha, y los campesinos y sus familias estuvieron retenidos durante 8 días a 500 metros del casco urbano de Icononzo, a la altura de la vereda Canadá Escocia, inclusive se cortó el servicio del agua en la zona. Según testimonios de quienes protestaron, en esa ocasión se presentó el caso de la identificación de algunos infiltrados de los grupos de inteligencia de las Fuerzas Armadas, ya que los campesinos reconocían a sus vecinos; posteriormente recibieron amenazas algunos líderes sociales dentro de los municipios en mención. Otro grupo de manifestantes que se desplazaba por la ruta hacia Boquerón (a orillas del río Sumapaz y que conecta con la vía Bogotá-Melgar) fue detenido por el Ejército, allí les pidieron los documentos de identidad y se tomaron fotografías a los manifestantes. Como lo manifestó en entrevista el concejal Víctor Márquez, lo que siguió a continuación fueron las amenazas, asesinatos y desplazamientos de personas de la región que participaron en las marchas, y sus ejecutores fueron civiles armados ${ }^{45}$.

\section{Conclusiones}

Todos estos acontecimientos ocurrieron en la región de Sumapaz, que comunica el suroccidente del país con Bogotá, y que por sus condiciones naturales ha servido de ruta para los diferentes grupos armados legales e ilegales, en la conexión entre los departamentos de Cundinamarca, Meta, Huila y Tolima. De allí la importancia de la zona como «corredor estratégico», llamado así por las posibilidades tanto militares como de entrada y salida de productos ilegales o de toma del poder, dentro de las dinámicas del conflicto armado en el país.

De igual manera, se puede evidenciar cómo las acciones de los grupos enfrentados que, utilizando la confrontación de guerra irregular, han desarrollado estrategias de lo que muchos autores incluyen dentro de la denominada «guerra sucia». Modalidad que ha sido frecuente en la zona, y que es representativa de los varios momentos de violencia que ha vivido el país desde la década de los años cuarenta, y que resulta siendo condición de las nuevas formas de conflicto armado dadas durante el periodo de la Guerra Fría y la posguerra.

Se evidenció igualmente la forma en que se han utilizado civiles armados con métodos no convencionales de hacer la guerra de forma casi heredada de prácticas anteriores. Y, al mismo tiempo, se buscó comprender cómo fueron las violencias en una región que no se ha considerado como particularmente virulenta, pero que sirve de paradigma para entender el conflicto armado colombiano, tan complejo y que tristemente sigue dejando víctimas en Colombia.

\section{Referencias}

Aguilera Peña, Mario. Las Farc: la guerrilla campesina, 1949-2010, ¿ideas circulares en un mundo cambiante?, actores armados y población civil. Bogotá: ASDI, Organización Internacional para las Migraciones, 2010.

\footnotetext{
${ }^{44}$ Diario de campo. Conversación informal en el municipio de Icononzo (Tolima) julio de 2018.

${ }^{45}$ Entrevista a Víctor Márquez, 9 de junio de 2018, Icononzo (Tolima).
} 
Alape, Arturo. El Bogotazo, memorias del olvido. Bogotá: Planeta, 2000.

Amnesty International. Colombie, Arrêtez les Massacres ! Paris : Editions Francophones d'Amnesty International, 1994.

Colombie : Droits de l'homme question d'urgence. Paris : Editions Francophones d'Amnesty International, 1988.

Aprile-Gniset, Jacques. La crónica de Villarrica. Bogotá: Ediciones Antropos, 1991.

Centro Nacional de Memoria Histórica. ¡Basta ya! Colombia: Memorias de guerra y dignidad. Bogotá: Imprenta Nacional, 2013.

. Guerrilla y población civil. Trayectoria de las FARC 1949-2013, Bogotá: Guerrilla y población civil. Trayectoria de las FARC 1949-2013. Bogotá: Imprenta Nacional, 2014.

. De los grupos precursores al Bloque Tolima (AUC). Bogotá: Imprenta Nacional, 2017.

Comité de Solidaridad con los Presos Políticos. El libro negro de la represión. Frente Nacional 1958-1974. Bogotá: Editorial Gráficas Mundo Nuevo, 1974.

Cubides, Fernando. «Narcotráfico y paramilitarismo: ¿un matrimonio indisoluble?». En El poder paramilitar, Alfredo Rangel. Bogotá: Planeta, 2005.

Echandía, Camilo. «El conflicto armado colombiano en los años noventa: cambios en las estrategias y efectos económicos». Revista Colombia Internacional 49 (2000).

Franco, Vilma Liliana. «Guerra irregular: entre la política y el imperativo moral». Estudios Políticos, n. 19 (2001): 37-67.

Galula, David. Contre-insurrection : théorie et pratique. Paris : Economica, 2008.

Giraldo, Javier S. J. «Miradas desveladas sobre la guerra interna», abril de 2003, Bogotá. Acceso el 12 de diciembre de 2018. https://www.javiergiraldo.org/spip.php?article17

González, José Jairo y Elsy Marulanda. Historias de frontera. Colonización y guerras en el Sumapaz. Bogotá: CINEP, 1990.

Londoño, Rocío. «Los nuevos hacendados de la provincia del Sumapaz (1890-1930)». En Territorios, regiones, sociedades, editado por Renán Silva. Bogotá: Universidad del Valle, Fondo Editorial CEREC, 1994.

. «Juan de la Cruz Varela: sociedad y política en la región de Sumapaz (1902-1984)». Tesis doctoral, Universidad Nacional de Colombia, Bogotá, 2012.

Londoño, Rocío y Medófilo Medina. «Eso también explica la muerte de Gaitán. Entrevista con José María Villarreal». Análisis Político, n. 38 (septiembre-diciembre de 1999): $55-70$. 
Marulanda, Elsy. Colonización y conflicto. Las lecciones del Sumapaz (Bogotá: Tercer Mundo Editores, IEPRI-UN, 1991).

Medina, Carlos. Autodefensas, paramilitares y narcotráfico en Colombia. Origen, desarrollo y consolidación. El caso "Puerto Boyacá". Bogotá: Editorial Documentos Periodísticos, 1990.

Münkler, Herfried, Viejas y nuevas guerras. Asimetría y privatización de la violencia, Madrid: Siglo XXI, 2005.

Ortiz, Carlos Miguel. Estado y subversión en Colombia. La violencia en el Quindío años 50. Bogotá: CEREC, 1985.

Pabón, Wilson. La muerte y los muertos en Colombia. Violencia política, víctimas y victimarios. Bogotá: FUAC, 2015.

Rodríguez, Saúl, La influencia de los Estados Unidos en el Ejército colombiano 1951-1959 (Medellín: La Carreta Editores, 2006).

Sánchez, Gonzalo. Guerras, memoria e historia. Bogotá: ICAHN, 2003.

«Los estudios sobre la Violencia. Balances y perspectivas». En Pasado y presente de la violencia en Colombia, compilado por Gonzalo Sánchez y Ricardo Peñaranda. Bogotá: La Carreta Editores, 2007.

Tovar Hermes. «Colonialismo, diversidad e intolerancia: la responsabilidad del historiador». En Pensar el pasado, editado por Carlos Miguel Ortiz Sarmiento y Bernardo Tovar Zambrano,33. Bogotá: AGN, UN, 1997.

Zapata, Rubén Darío. «Los medios masivos y el conflicto en Colombia». Pueblos, n. ${ }^{\circ} 42$ (junio 2010). http://www.revistapueblos.org/blog/2010/07/12/los-medios-masivosy-el-conflicto-en-colombia/ 